\title{
Structure and shape recovery characteristics of Ti-50.0\%Ni thermomechanically treated industrial wire
}

\author{
I.Yu. Khmelevskaya $^{\text {a1 }}$, S.D. Prokoshkin ${ }^{1}$, S.Yu. Makushev ${ }^{2}$, A.B. Bondarev ${ }^{3}$, V.A. Andreev ${ }^{3}$ \\ ${ }^{1}$ Moscow Institute of Steel and Alloys, Russia \\ ${ }^{2}$ Kurdymov Institute of Metal Physics, Moscow, Russia \\ ${ }^{3}$ Industrial Center MATEKS, Moscow, Russia
}

\begin{abstract}
The effect of post-deformation annealing (PDA) temperature in a range 300 to $700^{\circ} \mathrm{C}$ and induced stain ( 3 to $24 \%$ ) on shape recovery temperature range (SRTR) was studied for an industrial Ti-Ni wire. To determine the characteristic temperatures of martensitic transformations, a differential scanning calorimetry was used. SRTR was determined by the method of bending deformation followed by heating for shape recovery. The wire structure was studied by X-ray diffraction and TEM methods. The original structure of wire is a B19'- martensite or a mixture of B19', R -phase and B2- austenite containing a well-developed dislocation substructure. To obtain structure uniformity along the wire length, the PDA temperatures of $500-600^{\circ} \mathrm{C}$ are recommended. The SRTR at the wire of near-equiatomic Ti-Ni alloys produced by warm drawing can be controlled using PDA in the temperature range 400 to $700^{\circ} \mathrm{C}$. SRTR in the $70-100^{\circ} \mathrm{C}$ range is achieved by means of PDA at 400 to $650^{\circ} \mathrm{C}$ (SRTR increases in this PDA range). With the increasing of induced strain from 5 to $24 \%$, the high-temperature shape memory effect is appears and grows: a non-monotonic $\mathrm{A}_{\mathrm{F}}$ growth from 90 to $150^{\circ} \mathrm{C}$ and $\mathrm{SRTR}$ broadening are observed. Shape recovery parameters of studied wire are high: the maximum completely recoverable strain of $4-5 \%$, the maximum recoverable strain of $7-13 \%$, and they can be controlled using PDA.
\end{abstract}

\section{Introduction}

Techniques for regulation of functional properties (FP) are different for Ti-Ni shape memory alloys (SMA) of different composition. For the non-aging equiatomic and near-equiatomic Ti-Ni SMA, the basic method of FP control is thermomechanical treatment (TMT), including severe plastic deformation (SPD), forming various structures : from well-developed recovered and polygonized dislocation substructure to nanocrystalline structure [1-4]. Shape memory sensors and thermoregulators for fire-prevention devices are successfully used in practice [5]. The wire of "high-temperature" near-equiatomic Ti-Ni alloys is an optimum material for production of heatsensitive elements (fire sensors, starting arrangements). The aim of the present work is to study the effect of thermomechanical action parameters on the structure and FP of Ti-Ni industrial wire.

\section{Experimental}

Three Ti-Ni based alloys (1, 2 and 3) having near-equiatomic chemical composition were studied. The effect of post-deformation annealing (PDA) and induced strain (3 to $24 \%$ ) on shape recovery temperature range (SRTR) was studied for an industrial Ti-Ni wire.

This is an Open Access article distributed under the terms of the Creative Commons Attribution-Noncommercial License (http://creativecommons.org/licenses/by-nc/3.0/), which permits unrestricted use, distribution, and reproduction in any noncommercial medium, provided the original work is properly cited. 
After warm drawing, the wire samples were annealed in the 300 to $700^{\circ} \mathrm{C}$ range for $1 \mathrm{hr}$ and $30 \mathrm{~min}\left(\right.$ at $\left.700^{\circ} \mathrm{C}\right)$. To determine the temperature range of martensitic transformations (TRMT), a differential scanning calorimeter "Perkin Elmer" was used. SRTR and shape recovery characteristics were determined by the method of bending deformation followed by heating for shape recovery. The structure was studied by X-ray diffraction (DRON 3.0 diffractometer) and TEM (Tesla BS-540 microscope) methods.

\section{Results and Discussion}

\subsection{DSC, X- ray diffraction}

The DSC results show the R-phase presence in initial state after warm drawing and after PDA in $400^{\circ} \mathrm{C}$ in alloys 1 and 2. The $\mathrm{B} 2 \rightarrow \mathrm{R} \rightarrow \mathrm{B} 19^{\prime}\left(\mathrm{T}_{\mathrm{Rs}}=57^{\circ} \mathrm{C}\right.$ и $\left.\mathrm{T}_{\mathrm{Rf}}=46^{\circ} \mathrm{C}\right)$ transformation sequence on cooling and $\mathrm{B} 19^{\prime} \rightarrow \mathrm{B} 2$ on heating (Fig. 1a). In this case, the characteristic temperatures of direct martensitic transformation are $\mathrm{M}_{\mathrm{s}}=19^{\circ} \mathrm{C}$, $\mathrm{M}_{\mathrm{f}}$ below $-15^{\circ} \mathrm{C}$; characteristic temperature range of the reverse one-stage transformation are $\mathrm{A}_{\mathrm{s}}=48^{\circ} \mathrm{C}$, $\mathrm{A}_{\mathrm{f}}=77^{\circ} \mathrm{C}$.

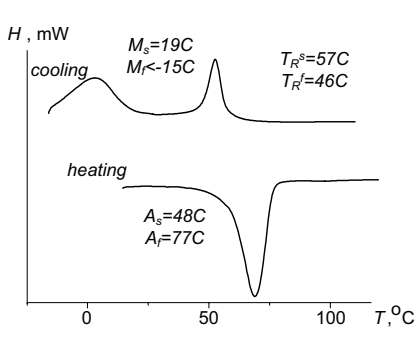

a

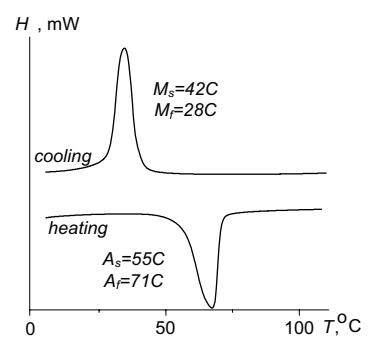

b

Fig. 1. DSC results for alloyl after PDA at $400^{\circ} \mathrm{C}(\mathrm{a})$ and $650^{\circ} \mathrm{C}(\mathrm{b})$.

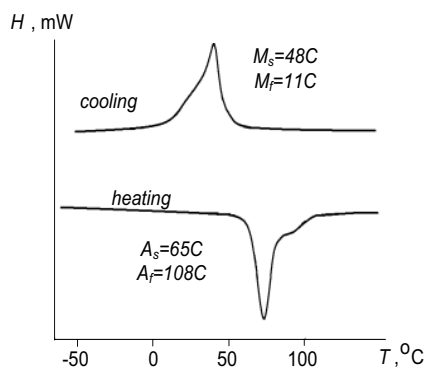

a

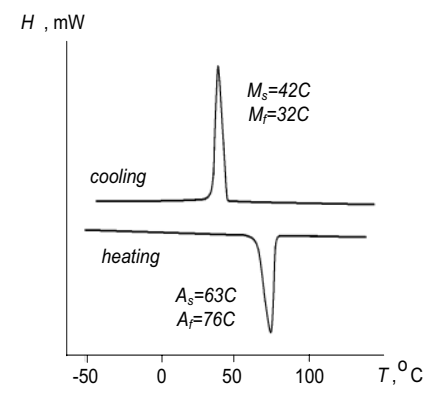

b

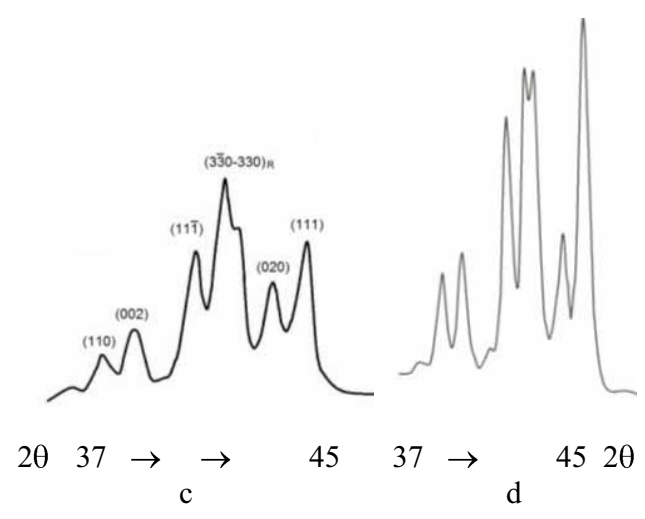

$452 \theta$

Fig. 2. DSC results and X-ray diffractograms for alloy 2 after $P D A$ at $400^{\circ} \mathrm{C}(\mathrm{a}, \mathrm{c})$ and $650^{\circ} \mathrm{C}(\mathrm{b}, \mathrm{d})$. 
In alloy 2 the peaks of the transformation heat on cooling and heating are asymmetrical and broadened, and one can not say definitely about $\mathrm{B} 2 \rightarrow \mathrm{R}$ transformation occurence. The shape of curves testifies to heterogeneity of wire structure. The $\mathrm{B} 2 \rightarrow \mathrm{R}$ transformation presences proved to be true by X-ray diffraction study of alloy 2 in initial warmdrawing state and after PDA at $400-600^{\circ} \mathrm{C}$ : there is a distinct $(330)-(3 \overline{3} 0)$ R-phase doublet in the diffractograms (Fig.1 c,d).

With the PDA temperature increasing to $600-700^{\circ} \mathrm{C}$, the structural heterogeneity is eliminated and lattice defectness is reduced. As a result of recrystallization, the temperature range of direct martensitic transformation of alloy 1 is shifted to higher temperatures: $\mathrm{M}_{\mathrm{s}}=42^{\circ} \mathrm{C}, \mathrm{M}_{\mathrm{f}}=28^{\circ} \mathrm{C}$ against 19 and $-15^{\circ} \mathrm{C}$ after PDA at $400^{\circ} \mathrm{C}$ (compare Figs. 1a and $1 \mathrm{~b}$ ), while less difference between the reverse MT temperatures was determined: $\mathrm{A}_{\mathrm{s}}=55^{\circ} \mathrm{C}, \mathrm{A}_{\mathrm{f}}=71^{\circ} \mathrm{C}$ against 48 and $77^{\circ} \mathrm{C}$ respectively (compare Figs. $1 \mathrm{a}$ and $1 \mathrm{~b}$ ).

After PDA at $600-700^{\circ} \mathrm{C}$, the $\mathrm{B} 2 \leftrightarrow \mathrm{B} 19^{\prime}$ transformation sequence realizes (Fig. $1 \mathrm{~b}, 2 \mathrm{~b}$ ). A significant shortening of direct and reverse MT ranges in alloy 2 after PDA at $650^{\circ} \mathrm{C}$ is observed (Fig. 2 b). The transformation sequence (on cooling and on heating) $\mathrm{B} 2 \leftrightarrow \mathrm{B} 19^{\prime}$ realizes like in alloy 1 .

\subsection{TEM}

The TEM images analysis of $\mathrm{Ti}-\mathrm{Ni}$ alloys with close to equiatomic composition is complicated because B19' martensite due to features of the mechanism of transformation contains a rather high disposition density (Fig.3). The well-developed dislocation substructure of martensite is superposed on the dislocation substructure created in austenite by thermomechanical treatment. In this case, to differentiate between these two substructures (inherited from austenite and inherent in martensite) is not always possible. The TEM analysis also reveals some quantity of B2- austenite (and/or R - phase) at room temperature.

As can be seen at Fig. 3, in initial state after warm drawing, the alloy 1 has mixed structure including martensite, $\mathrm{R}$ - phase and austenite with very high dislocation density. The visual analysis of residual austenite areas shows that warm drawing forms a well-developed dislocation substructure of cellular type in austenite, termines a strong deformation hardening of the alloy. The corresponding both azimuthally and radial broadening of reflexes in the electron diffraction pattern observed (Fig. $3 \mathrm{~b}$ ). This is a consequence the imperfectness of crystal lattice orientation caused by the distortions brought by deformation- and transformation induced hardening.

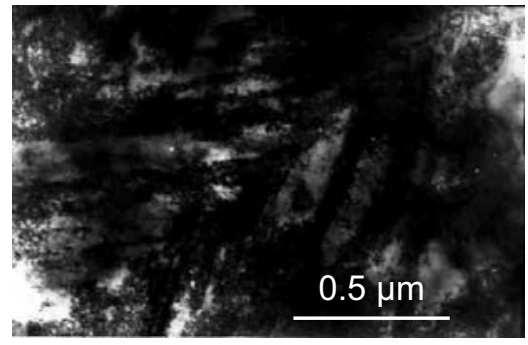

a)

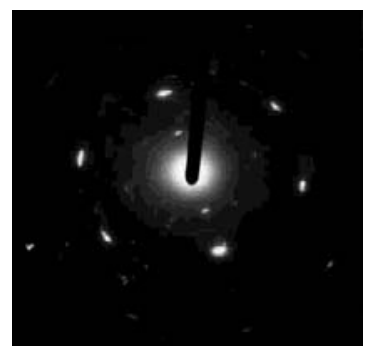

b)

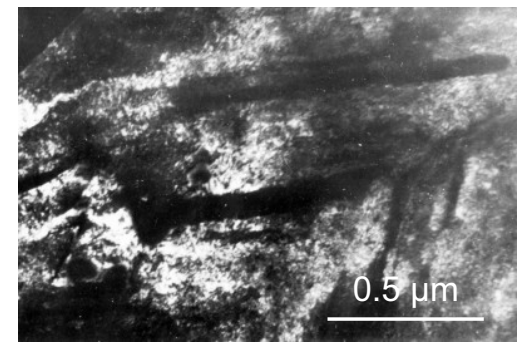

c)

Fig. 3. Structure of alloy 1 after warm drawing: zone axis close to $<311>B 2$; a-bright-field image, b- electron diffraction pattern from "a", c- dark-field image.

The post-deformation annealing of alloy 1 at $400^{\circ} \mathrm{C}$ leads to obvious changes in the dislocation substructure. The 50-200 nm subgrains inherited by martensite from austenite are observed (Fig. 4). In this case, the average orientation (positions of the diffraction reflex centers) and misorientation across the selected area (the length of arc reflexes) do not change, a fragmentation of arc reflexes becomes evident (Fig.4). That testifies to polygonization process development and polygonized dislocation substructure formation under $400^{\circ} \mathrm{C}$ - annealing $[3,4]$. 
The structure of alloy 3 in the initial as-drawn state is similar to the structure of alloy 1. PDA at high temperature $\left(650^{\circ} \mathrm{C}\right)$ followed by water-cooling i.e., ordinary quenching, leads to formation of the martensite structure with high dislocation density which is typical for quenched near-equiatomic $\mathrm{Ti}-\mathrm{Ni}$ alloys.

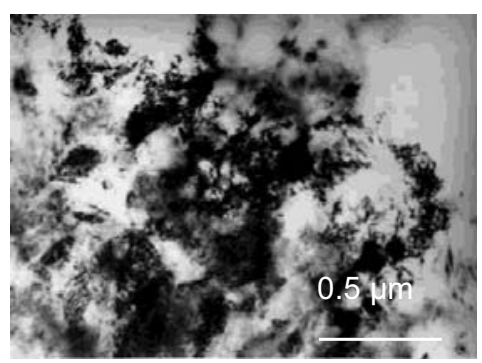

a)

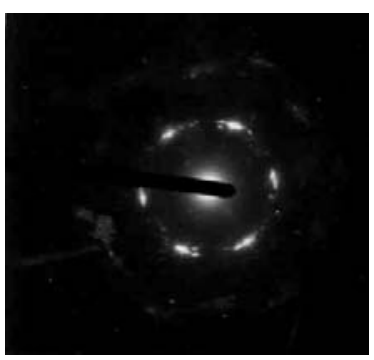

b)

Fig.4. Structure and electron diffraction pattern of alloy 1 after drawing and annealing at $400^{\circ} \mathrm{C}$ : a - bright field image; b-electron diffraction from "a".

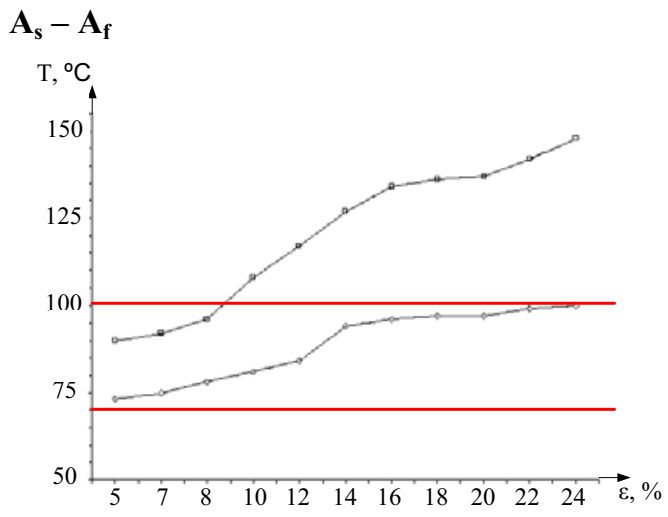

a)

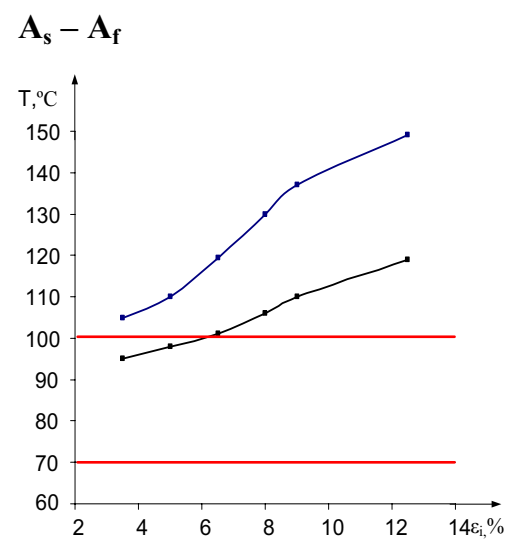

b)

Fig.5. SRTR of alloy 3 after PDA at $700^{\circ} \mathrm{C}(\mathrm{a})$ and alloy 1 after PDA at $650^{\circ} \mathrm{C}(\mathrm{b})$.

As an example, typical dependences of SRTR on the induced strain after different regimes of PDA are given in Fig. 6 (a-d) for alloy 2.

The range of $\varepsilon_{\mathrm{i}}$ values which provides the required temperature range of shape recovery, also tends to broadening and shifts aside to lower values with annealing temperature raising: for PDA at $400^{\circ} \mathrm{C}$ and $500^{\circ} \mathrm{C}$ the $\varepsilon_{\mathrm{i}}$ range extends contains values from $8 \%$ to $14 \%$, for PDA at $550^{\circ} \mathrm{C}-$ from 8 to $13.5 \%$, for PDA at $640^{\circ} \mathrm{C}$ from 4.5 to $12 \%$ (Fig. 6 a-d) and for PDA at $700^{\circ} \mathrm{C}$ from $5-10.5 \%$. For alloy 2 , it is possible to recommend PDA at 400,500 and $550^{\circ} \mathrm{C}$ as optimum regimes because a combination of high shape recovery characteristics with the required temperature range of their realization is observed. 

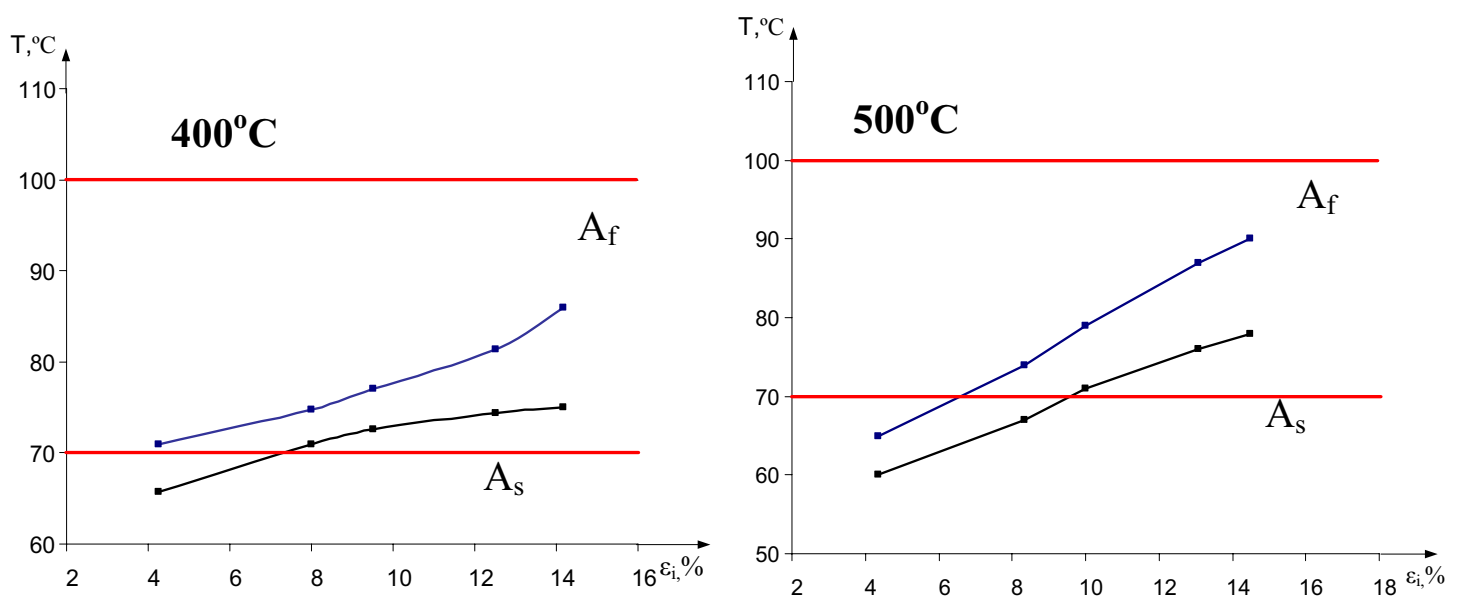

a

b
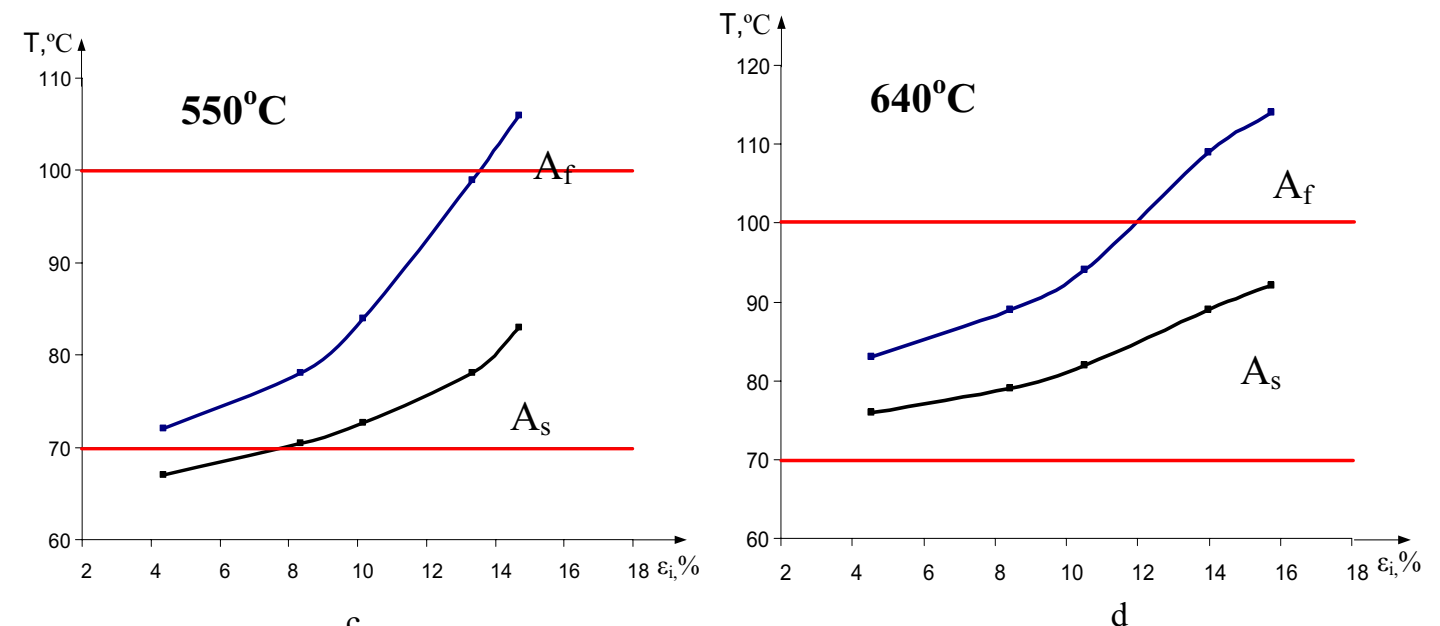

Fig. 6. Dependencies of SRTR on induced strain after PDA at $400(a), 500(b), 550(c)$ and $640^{\circ} \mathrm{d}$ (d)

\subsection{Temperature range of shape recovery}

As it has been shown above, the wire in initial state after warm drawing accumulates a high level of strain hardening. PDA leads to the alloy softening due to recovery, polygonization and recrystallization processes development, thus TRMT and SRTR are shifted to higher temperatures. The initial induced strain (which is completely or partialy recovered on heating) also shifts the transformation range to higher temperatures as compared to the temperatures determined without loading by DSC method. Thus, to obtain the required shape recovery (working) range from 70 to $100^{\circ} \mathrm{C}$, it is necessary to find out the PDA regimes providing this temperature range for a wide range of induced strains.

A typical dependence of SRTR on the induced strain is presented in Fig. 5a for $1.0-\mathrm{mm}$ diameter wire in alloy 3 after PDA at $700^{\circ} \mathrm{C}$ (recrystallized structure of austenite). One can see non-monotonous change and broadening of SRTR with more intensive raising of $A_{f}$ temperature (from $90^{\circ} \mathrm{C}$ to $148^{\circ} \mathrm{C}$ ) in the induced strains range from $\varepsilon_{i}=8$ to $18 \%$. That illustrates the high-temperature SME realization, caused by the martensite plastic 
deformation [6]. For the samples of alloy 1 annealed at $650^{\circ} \mathrm{C}$, the $\mathrm{A}_{\mathrm{s}}-\mathrm{A}_{\mathrm{f}}$ temperatures do not lay into the required temperature range of $70-100^{\circ} \mathrm{C}$ (Fig.5b).

\subsection{Shape recovery characteristics}

Shape recovery parameters of wire: maximum recoverable strain $\left(\varepsilon_{\mathrm{r}}{ }^{\max }\right)$, residual irreversible strain $\left(\boldsymbol{\varepsilon}_{\mathbf{f}}\right)$ and shape recovery rate $\left(\varepsilon_{\mathrm{r}} / \varepsilon_{\mathrm{i}}\right)$, were determined as a function of induced strain, and PDA regimes (Fig.7).

It is necessary to note that all three alloys have very high shape recovery parameters for this category of "hightemperature" alloys: the maximum completely $(100 \%)$ recoverable strain $\varepsilon_{\mathrm{r}, 1}{ }^{\max }=4 \div 5 \%$; the maximum recovery strain $\varepsilon_{\mathrm{r}}{ }_{\max }=7-13 \%$, and shape recovery rate $\varepsilon_{\mathrm{r}} / \varepsilon_{\mathrm{i}}$ not less than $80 \%$.
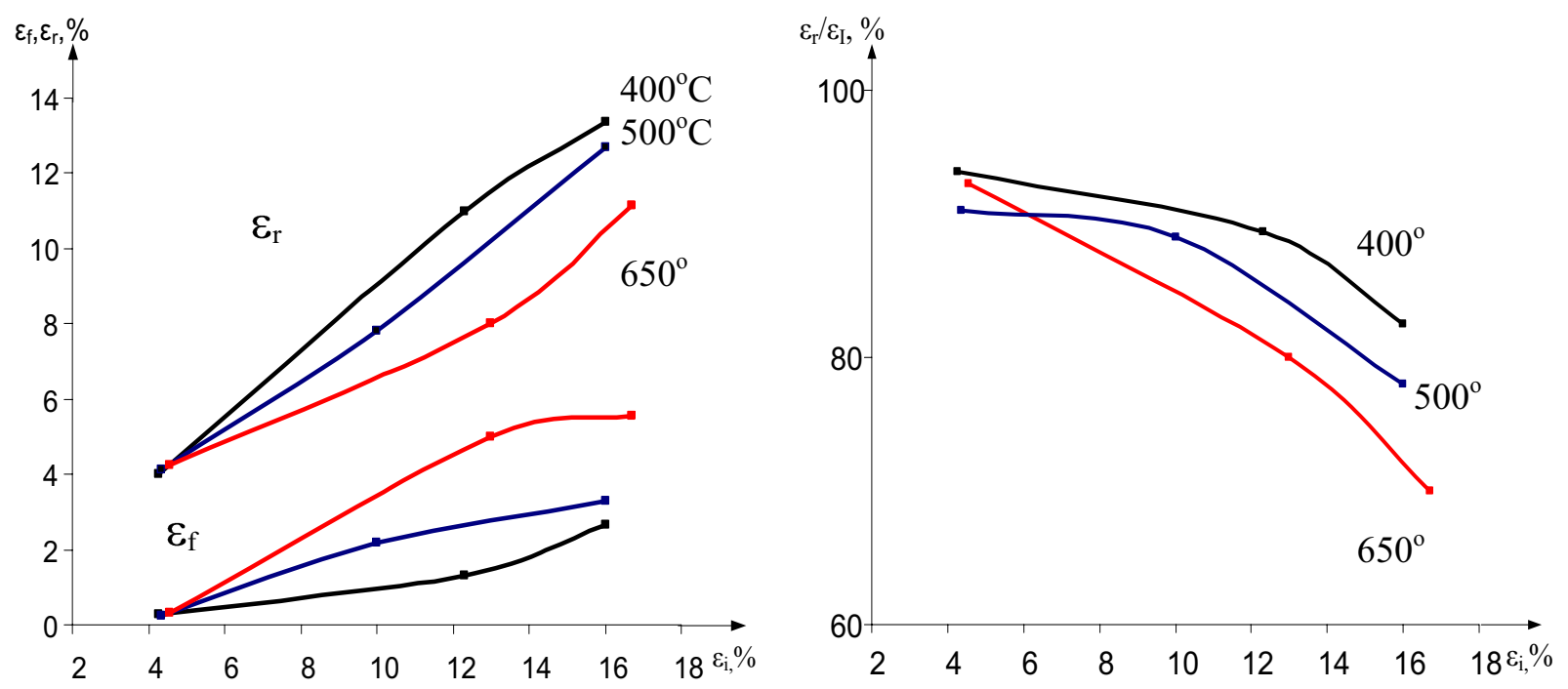

Fig. 7. Dependencies of shape recovery characteristics on induced strain and PDA temperature (alloy 2).

Besides the DSC analysis shows that the alloys have different phase composition at room temperature. Consequently, the strain inducing SME is accumulated by different structural mechanisms in alloys 1, 2 and 3 after different PDA regimes. Thus, in alloys 1 and 3 after PDA at $650^{\circ} \mathrm{C}$, the structure of wire before deformation is mainly martensite, and the induced strain is accumulated by reorientation of B19'- martensite. In alloys 1 and 2 after PDA at $400^{\circ} \mathrm{C}$, the induced strain is accumulated not only by the reorientation of martensite but also by the formation of stress-induced martensite from B2- and R-phases. Obviously, in this case deformation is accompanied by smaller irreversible distortions, that promotes more complete shape recovery.

\section{Conclusions}

1. The existing technology of $\mathrm{Ti}-\mathrm{Ni}$ wire warm drawing not always provides homogeneous structure in diam. $1.0-2.0 \mathrm{~mm}$ sections. . The structure of the as-drawn wire represents itself B19'- martensite or a mixture of B19', R -phase and B2- austenite containing a well-developed dislocation substructure. To obtain structure uniformity, the PDA temperatures of $500-600^{\circ} \mathrm{C}$ are recommended. It should be taken into consideration when forming a working shape of SME elements.

2. The SRTR of Ti-Ni near-equiatomic wire produced by warm drawing can be controlled using PDA in the temperature range 400 to $700^{\circ} \mathrm{C}$. SRTR of $70-100^{\circ} \mathrm{C}$ is achieved by means of PDA at 400 to $650^{\circ} \mathrm{C}$ (SRTR increases in this PDA range). 
The choice of optimum PDA temperature depends on melting composition of alloy. For example, the PDA temperature recommended for alloy 1 wire of is $400^{\circ} \mathrm{C}$, for alloy 2 is $400-550^{\circ} \mathrm{C}$, and for alloy $3^{-}-550-650^{\circ} \mathrm{C}$, with $1 \mathrm{hr}$ exposure.

3. With the increasing of induced strain from 5 to $24 \%$, the high-temperature shape memory effect appears and grows: a non-monotonic $\mathrm{A}_{\mathrm{f}}$ growth from 90 to $150^{\circ} \mathrm{C}$ and SRTR broadening are observed.

4. Shape recovery parameters of studied $\mathrm{Ti}-\mathrm{Ni}$ wires are high: the maximum completely recoverable strain of $4-5 \%$, the maximum recovery strain of $7-13 \%$, and they can be controlled using PDA.

\section{References}

[1] S.D. Prokoshkin, V. Brailovski, I.Yu. Khmelevskaya et al., Met.Sci. Heat Treat.47, 182 (2005)

[2] S.D. Prokoshkin, I.Yu. Khmelevskaya, S.V. Dobatkin et al., Acta Mater. 53, 2703 (2005)

[3] V. Brailovski, S.D. Prokoshkin, I.Yu. Khmelevskaya Materials Transactions 47,785 (2006)

[4] S.D.Prokoshkin, , K.E. Inaekyan, V. Demers et al., Mat. Sci. and Eng.A, 481 (2008)

[5] Shape memory materials, v. 4, edited by V.A. Likhachev, St.-Peterburg SPBU publ.(1998)

[6] S.D. Prokoshkin, S. Turenne, I.Yu. Khmelevskaya et al., Canadian Met. Quart. 39, 225(2000) 